ISSN 2179-6750

\title{
Relação entre nível de conhecimento, atitude e controle metabólico em indivíduos com diabetes mellitus tipo 1: um problema de saúde pública
}

\author{
Rafael Pinto Palma, Ana Paula Ferreira
}

\begin{abstract}
Resumo
O diabetes mellitus tipo 1 pode ser caracterizado como um transtorno metabólico resultantes de problemas na secreção e/ou da ação da insulina. Avaliar o nível de conhecimento e atitude de jovens com DM1(Diabetes Mellitus Tipo 1) em relação à doença e correlacionar estes escores as taxas de hemoglobina glicada (HbA1c). Trata-se de um estudo de natureza descritiva do tipo transversal, que avaliou 13 indivíduos de ambos os sexos, sendo incluídos aqueles com idade entre 18 e 30 anos, com diagnóstico prévio de DM1 confirmado em exames laboratoriais e que possuíam dados referentes à $\mathrm{HbA1C}$ realizada em até três meses antes da avaliação. Todos os indivíduos foram submetidos a anamnese e em seguida responderam aos questionários ATT-19 (Attitude Questionnaire) e DKN-A (Diabetes Knowledge Questionnaire) com duração média de 20 minutos. Os 13 indivíduos com DM1, 69,2\% do sexo feminino, apresentavam como tempo médio de exposição à doença $12,7 \pm 5,4$ anos (média \pm desvio padrão). A média de idade da amostra investigada foi de 24,9 \pm 3,6 anos (média \pm desvio padrão, amplitude de 18 a 30 anos). A correlação entre o nível de conhecimento avaliado pelo DKNA e o controle metabólico obtido através do resultado da última $\mathrm{HbA1c}$, foi desprezível $\mathrm{r}=0,11, \mathrm{p}=0,70$, bem como a correlação entre o nível de atitude avaliada pelo ATT-19 e o controle metabólico $r=0,29, p=0,33$, apresentando uma baixa atitude frente a doença, mesmo demonstrando um conhecimento prévio positivo da mesma. Verificamos que os indivíduos com DM1 apresentaram escores insatisfatórios de controle metabólico quando analisado a média encontrada da $\mathrm{HbA1c}$ e no escore obtido através do questionário que avalia a atitude (ATT-19). Acreditamos que isto pode ter ocorrido pela negligência dos mesmos em relação à sua condição de saúde e na busca ativa de informação em campanhas e programas de saúde que visam à orientação deste grupo de pacientes.
\end{abstract}

Descritores: Diabetes mellitus tipo 1; Conhecimentos; Atitudes e Prática em Saúde; Atitude frente à saúde. 